\title{
Design of Multiband Printed Flexible antenna for Body Wearable Applications
}

\author{
Vilas Ubale ${ }^{1}$, Dr. O. S. Lamba ${ }^{2}$ \\ ${ }^{1}$ Department of Electronics and Communication Engineering, Suresh GyanVihar UniversityJaipur, India, \\ vilasubale1978@gmail.com, \\ ${ }^{2}$ Department of Electronics and Communication Engineering, Suresh GyanVihar UniversityJaipur, India \\ onkar.lamba@mygyanvihar.com
}

\begin{abstract}
Design of Wearable antennas for Body Wireless Sensor Networks (BWSN) especially for healthcare systems shall provide opportunities in wireless monitoring, communication, and effective treatment. In this paper, we present the design and analysis of a multi-band printed flexible antenna for ubiquitous monitoring applications. The proposed antenna is designed on a cotton material and consists of a circular patch and ground plane. The cotton material is highly flexible and has a dielectric constant of 1.60, dielectric tangent of 0.04 and, a thickness of $1 \mathrm{~mm}$. The antenna is fed using a microstrip feedline with an impedance of $50 \Omega$. The antenna facilitates operation at the fundamental frequency band of $2.4 \mathrm{GHz}$ and multi-band operation at $4,5.5$ and $7.4 \mathrm{GHz}$ with $-10 \mathrm{~dB}$ reflection coefficient bandwidths of $2.4-2.5 \mathrm{GHz}, 4-4.12 \mathrm{GHz}$, $5.25-5.65 \mathrm{GHz}$ and, $7.2-7.5 \mathrm{GHz}$ respectively. The antenna offers stable electrical characteristics in both frequency and time domain making it suitable for wearable applications in healthcare systems.
\end{abstract}

Key words : Cotton substrate, Flexible antenna, multiband, Wearable

\section{INTRODUCTION}

Flexible wearable antenna design has grossing research interest amongst researchers due to the need for wireless monitoring of patients, especially in critical health care scenarios such as corona virus pandemic. In the case of wireless monitoring of patients, appropriate sensors/devices such as temperature sensors, ECG recording devices, etc... can be mounted on the patient's body and body parameters such as temperature, heart rate, ECG signal can be recorded. This recorded signal needs to be transmitted wirelessly to a remote location where doctors/paramedical staff can monitor the patient's health and provide required medical assistance to the patients.

In order to transmit the body parameters, antennas, specifically, flexible wearable antennas are required. In order to design wearable antennas, textile materials such as cotton, silk, polyester and, cordura have been proposed in [1]. Flexible wearable antennas require planar structure, flexible conductive material for patch and ground structures, and most importantly flexible dielectric materials for realizing substrate structures [2]. The characteristics of the dielectric materials used for designing flexible wearable antennas play a crucial role in the behavior of the antenna. Other factors affecting the performance of the flexible wearable antennas are:

1. Dielectric constant (relative permittivity) of the substrate: Dielectric properties of textile materials such as cotton, silk, polyester have been studied in [3]-[5].

2. Thickness of the dielectric substrate: The quality factor that relates to the bandwidth of the antenna is largely influenced by the thickness of the dielectric substrate. Bandwidth (B) of the antenna which is inversely proportional to the antenna quality factor $(\mathrm{Q})$. The antenna quality factor is largely dependent on the space wave $\left(\mathrm{Q}_{\mathrm{rad}}\right)$ losses, the conduction $\left(\mathrm{Q}_{c}\right)$ losses, the surface waves $\left(\mathrm{Q}_{s w}\right)$ and dielectric $\left(\mathrm{Q}_{\mathrm{d}}\right)$ losses. For thin substrates, usually with $\mathrm{h}<<\lambda_{0}$, the quality factor is largely dependent on $\mathrm{Q}_{\mathrm{rad}}$, with $\mathrm{Q}_{\text {rad }}$ inversely proportional to the substrate thickness [6].

3. Electrical Surface Conductivity for fabrics that are conductive in nature: Fabrics are planar materials in nature and hence their electrical behavior can be quantified by surface resistance measured in terms of surface resistivity. The conductivity $\sigma$, in terms of surface resistivity $\rho_{\mathrm{s}}$ is given as: $\sigma=1 /(\rho s \times h)$, where $h$ is substrate thickness. In general, fabrics used as substrates must have low electrical surface resistance in order to minimize the electrical losses and thereby increase antenna efficiency [7]-[8].

4. The moisture content of the fabric: The moisture absorbed by the fabrics changes the properties of the fabrics. The smaller the fabric moisture absorption rate, the more stable are antenna characteristics [9].

5. Mechanical deformations of the dielectric: The human body has many curvatures on it. Wearable flexible antennas when embedded on them, adapts with the human body curves resulting in mechanical deformations in the fabrics used as substrate. This mechanical deformation can change the electromagnetic properties thereby influencing the performance of the antenna [10].

Over the decade, many researchers have proposed flexible wearable antenna designs through literature, however, the first wearable antenna design was reported in 2001, where a dual-band PIFA on unspecified material was presented 
[11]. A detailed literature review on textile material used for flexible wearable antenna design is presented by us in [12]. In this paper, we have presented a highly flexible wearable antenna developed on cotton material. The presented antenna provides quad-band operation at 2.4 $\mathrm{GHz}$ (in ISM), $4 \mathrm{GHz}, 5.5 \mathrm{GHz}$ (in WLAN) and, $7.4 \mathrm{GHz}$ frequency band.

Flexible antennas have various applications such as smart textile, military applications, Flexible electronics on foil and intelligent smart cards [13].

The Ultra-Wide Band antennas are also used for body wearable applications in the frequency range of $3.1 \mathrm{GHz}$ to 10.6 GHz. The frequencies of ultra wide band range are used in wireless applications like WiMAX, WLAN, etc.[14].

\section{ANTENNA DESIGN}

The antenna consists of a circular radiating patch of radius ' $a$ '. The dimensions of the antenna are calculated by following equations proposed in [6]. The antenna is designed to operate at the resonant frequency $f_{r}=2.45$ GHz. The radius 'a' of the circular patch antenna is calculated using eq (1) as:

$$
a=\frac{F}{\left\{1+\frac{2 h}{\pi \varepsilon_{r} F}\left[\ln \left(\frac{\pi F}{2 h}\right)+1.7726\right]\right\}^{1 / 2} \ldots(1)}
$$

with

$$
F=\frac{8.791 \times 10^{9}}{f_{r} \sqrt{\varepsilon_{r}}}
$$

Where $\mathrm{h}=0.1 \mathrm{~cm}$ is the height of substrate/ thickness of substrate, $f_{r}=2.45 \mathrm{GHz}$ is the antenna resonant frequency, $\varepsilon_{r}=1.60$ is the dielectric constant of cotton. Following equations (1) and (2), the theoretical value of radius 'a' of the circular patch is $26.5 \mathrm{~mm}$.

The feed line chosen is a microstrip feed line which is easy to design, model, and fabricate. The feed line length is approximately $75 \%$ of the radius of the circular patch. The feed-width depends on the antenna impedance. The antenna impedance is considered as $50 \Omega$. This is because most of the RF devices have characteristics impedance of either $50 \Omega$ or $75 \Omega$. Hence, when these devices are connected to the antenna; antenna must be perfectly matched to avoid mismatch losses. The feed-width can be calculated using equations presented in [15] given as:

$$
\begin{aligned}
& \text { For } \mathrm{W} / \mathrm{h} \leq 1: \\
& \varepsilon_{r e}=\frac{\varepsilon_{r}+1}{2}+\frac{\varepsilon_{r}-1}{2}\left\{\left(1+12 \frac{h}{W_{f}}\right)^{-0.5}+0.04\left(1-\frac{W_{f}}{h}\right)^{2}\right\} \ldots(3 \\
& Z_{c}=\frac{\eta}{2 \pi \sqrt{\varepsilon_{r e}}} \ln \left(\frac{8 h}{W_{f}}+0.25 \frac{W_{f}}{h}\right) \ldots(4)
\end{aligned}
$$

Wheren $=120 \pi \Omega$ is the wave impedance in free space

For $\mathrm{W} / \mathrm{h} \geq 1$ :

$$
\begin{aligned}
& \varepsilon_{r e}=\frac{\varepsilon_{r}+1}{2}+\frac{\varepsilon_{r}-1}{2}\left(1+12 \frac{h}{W_{f}}\right)^{-0.5} \ldots(5) \\
& Z_{c}=\frac{\eta}{\sqrt{\varepsilon_{r e}}}\left\{\frac{W_{f}}{h}+1.393+0.677 \ln \left(\frac{W_{f}}{h}+1.444\right)\right\}^{-1} \ldots
\end{aligned}
$$

In most cases, $\mathrm{W} / \mathrm{h}$ is usually greater than 1 . Hence, we use equations 5 and 6 . With $\mathrm{Z}_{c}=50 \Omega$, theoretical value of $\mathrm{W}_{f}$ (feed width) $=3.2 \mathrm{~mm}$. The feedline is connected to a coaxial connector. The antenna has overall dimensions of $84 \times 72.5 \mathrm{~mm}^{2}$. The detailed antenna dimesions are presented in Table 1. The simulation is carried out using EM simulation software HFSS. Figure 1 shows the geometrical structure of the presented antenna.
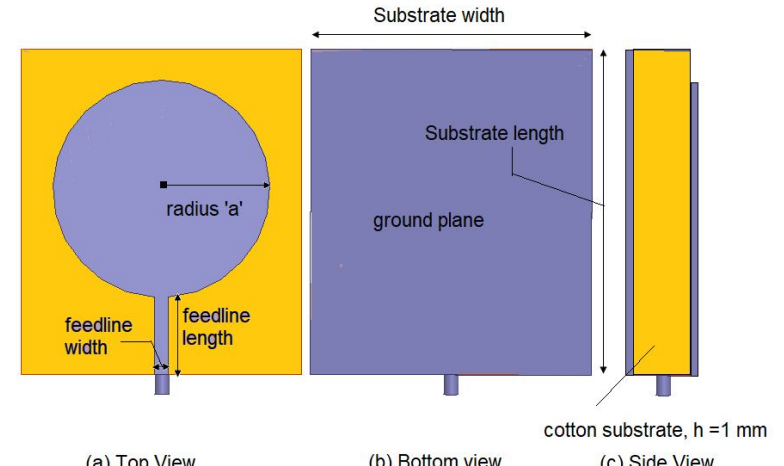

(a) Top View

(b) Bottom view

(c) Side View

Figure 1: Antenna configuration of the presented flexible wearable antenna.

Table 1: Antenna dimension of the presented flexible wearable antenna

\begin{tabular}{|l|c|}
\hline \multicolumn{1}{|c|}{ Antenna Parameter } & $\begin{array}{c}\text { Optimized value of the } \\
\text { antenna parameter }\end{array}$ \\
\hline Radius 'a' & $28 \mathrm{~mm}$ \\
\hline Feedline length, $\mathrm{L}_{f}$ & $20.5 \mathrm{~mm}$ \\
\hline Feedline width, $\mathrm{W}_{f}$ & $3.5 \mathrm{~mm}$ \\
\hline Substrate length, $\mathrm{L}_{\text {sub }}$ & $84 \mathrm{~mm}$ \\
\hline Substrate width, $\mathrm{W}_{\text {sub }}$ & $72.5 \mathrm{~mm}$ \\
\hline Substrate thickness, $\mathrm{h}$ & $1 \mathrm{~mm}$ \\
\hline
\end{tabular}

\section{RESULTS AND DISCUSSION}

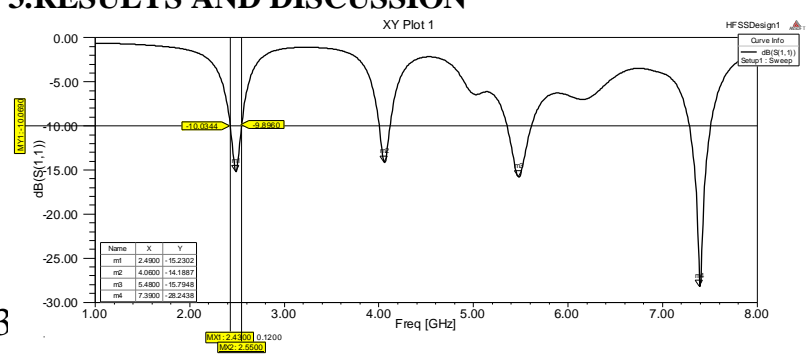

Figure 2: Simulated reflection co-efficient [dB] characteristics of presented flexible wearable antenna 


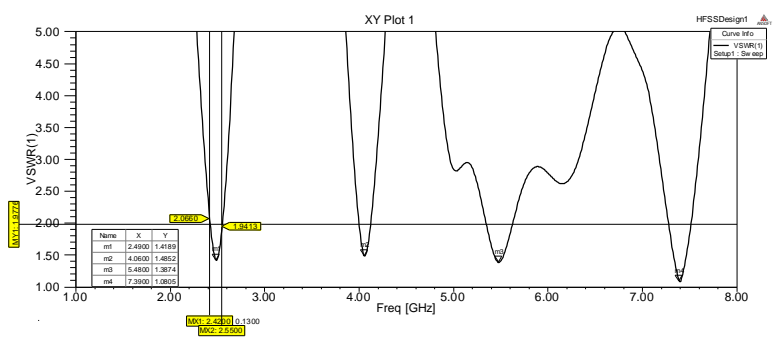

Figure 3: Simulated VSWR characteristics

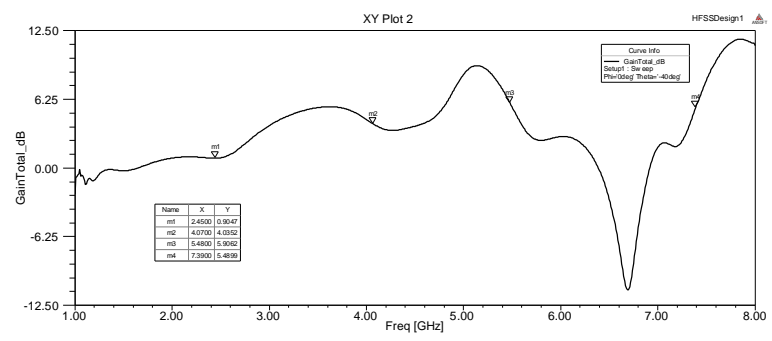

Figure 4: Simulated Gain

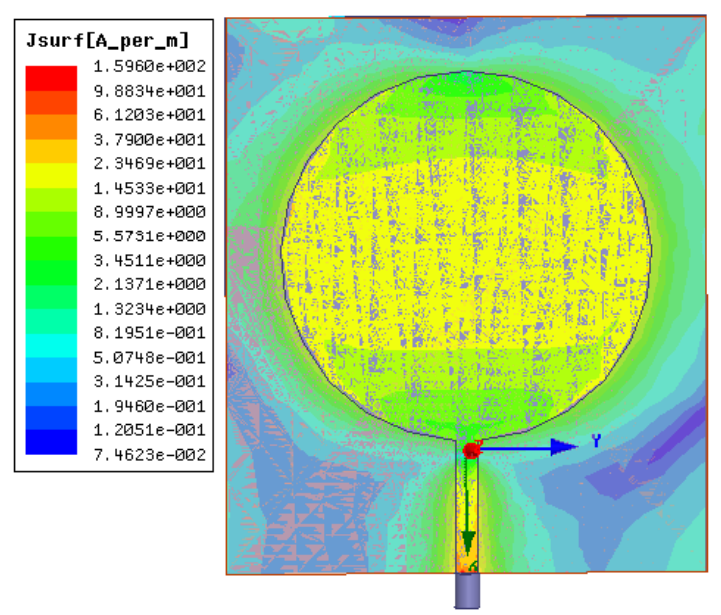

Figure 5: Simulated surface current distribution at $2.45 \mathrm{GHz}$

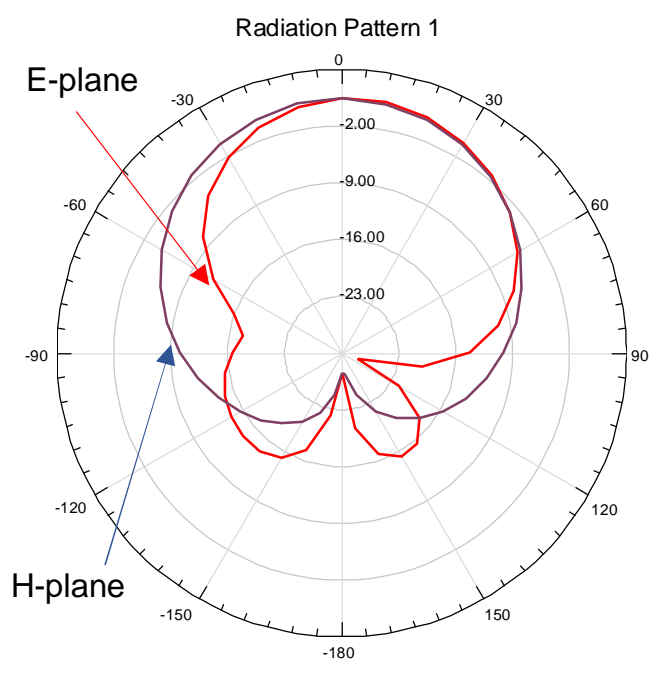

Figure 6: Simulated radiation pattern along $\mathrm{E}$ and $\mathrm{H}$ plane at $2.45 \mathrm{GHz}$
The presented antenna provides multi-band operation at $2.45 \mathrm{GHz}$ (fundamental frequency), $4 \mathrm{GHz}, 5.5 \mathrm{GHz}$, and 7.4 GHz as shown in Figure 2. The presented antenna has simulated $-10 \mathrm{~dB}$ reflection coefficient bandwidths of 2.4 $2.5 \mathrm{GHz}, 4-4.12 \mathrm{GHz}, 5.25-5.65 \mathrm{GHz}$, and $7.2-7.5$ GHz. Figure 3 shows the simulated VSWR characteristics of the presented antenna. The antenna has simulated gains of $0.9,4,5.9$, and 5.48 at operational frequency bands of $2.45 \mathrm{GHz}, 4 \mathrm{GHz}, 5.5 \mathrm{GHz}$ and, $7.4 \mathrm{GHz}$ respectively as shown in Figure 4. The current distribution at $2.45 \mathrm{GHz}$ shows that most of the radiation is done by the circular patch as the current is largely concentrated along the surface of the circular patch as shown in Figure 4.The radiation characteristics are perfectly omni-directional along H-plane and directional along the E-plane. The backlobe radiation is minimal along E-plane; hence the antenna is perfectly suited for implant/body medical wearable applications.

\section{CONCLUSIONS}

In this paper, we have presented the design and analysis of a highly flexible printed wearable antenna for body wearable applications in the wireless health monitoring system. The proposed antenna is small, light-weight, and highly flexible in nature. The antenna provides quad-band operation at $2.45 \mathrm{GHz}, 4 \mathrm{GHz}, 5.5 \mathrm{GHz}$ and, $7.4 \mathrm{GHz}$ frequency bands. The antenna has reasonable reflection coefficient bandwidths and gains across the operational frequency bands. The antenna has directional E plane and omni-directional $\mathrm{H}$ plane characteristics at operational frequency bands. Stable frequency and time domain characteristics of the presented antenna makes it a suitable candidate for wearable applications in wireless monitoring scenarios.

\section{REFERENCES}

1. Rita Salvado, Caroline Loss, Ricardo Gonçalvesand Pedro Pinho, "Textile Materials for the Design of Wearable Antennas: A Survey", Sensors, 2012, 12, pp. 15841-15857; doi:10.3390/s121115841

2. Liu, N.; Lu, Y.; Qiu, S.; Li, P. Electromagnetic Properties of Electro-Textile for Wearable Antennas Applications. Front. Electr. Electron. Eng. China 2011, 6, pp. 553-566. https://doi.org/10.1007/s11460-011-0182-7

3. Bal, K.; Kothari, V.K. Measurement of Dielectric Properties of Textile Materials and Their Applications. Indian J. Fibre Text. 2009, 34, 191199.

4. Morton, W.E.; Hearle, W.S. Physical Properties of Textile Fibres, 4th ed.; Woodhead Publishing: Cambridge, UK, 2008.

5. Sankaralingam, S.; Bhaskar, G. Determination of Dielectric Constant of Fabric Materials and Their Use as Substrates for Design and Development of Antennas for Wearable Applications. IEEE Trans. Instrum. Meas. 2010, 59, 3122-3130.

6. Balanis, C.A. Antenna Theory: Analysis and Design, 3rd ed.; Wiley Interscience: Hoboken, NJ, USA, 2005 
7. Webster, H.G. The Measurement, Instrumentation, and Sensors Handbook; Springer: Berlin, Germany, 1999.

8. Maryniak, W.A.; Uehara, T.; Noras, M.A. Surface Resistivity and Surface Resistance MeasurementsUsing a Concentric Ring Probe Technique. Application Note; Trek, Inc.: Medina, NY, USA, 2003; pp. 1-4.

9. Hertleer, C.; Laere, A.V.; Rogier, H.; Langenhove, L.V. Influence of Relative Humidity on Textile Antenna Performance. Text. Res. J. 2009, 80, 177183.

https://doi.org/10.1177/0040517509105696

10. Locher, I.; Klemm, M.; Kirstein, T.; Tröster, G. Design and Characterization of Purely Textile Patch Antennas. IEEE Trans. Adv. Pack. 2006, 29, 777788.

11. Salonen, P.; Keskilammi, M.; Rantanen, J.; Sydanheimo, L. A Novel Bluetooth Antenna on Flexible Substrate for Smart Clothing. In Proceedings of Conference of IEEE International Conference on Systems, Man, and Cybernetics, Tucson, AZ, USA, 7-10 October 2001; pp. 789-794.

12. Vilas S. Ubale, O. S. Lamba, Flexible Wearable Antennas for Body AreaNetwork, International Journal of Recent Technology and Engineering (IJRTE)ISSN: 2277-3878, Volume-8 Issue-5, January 2020, pp 1561-1565

13. M.Pandimadevi, R.Tamilselvi, M.Parisa Beham, Design Issues of Flexible Antenna -A Review, International Journal of Advanced Trends in Computer Science and Engineering, Volume 8, No.4, July - August 2019, pp 1386 - 1394.

14. V. Subba Reddy, M. Siva Ganga Prasad, B T P Madhav, Design and Implementation of Dual Notch Band Characteristics in UWB Antenna for Wireless Personal Communications, International Journal of Advanced Trends in Computer Science and Engineering, Volume 8, No.4, July - August 2019, pp $1719-1725$. https://doi.org/10.30534/ijatcse/2019/100842019

15. Jia-Sheng Hong, M. J. Lancaster, Microstrip Filters for RF/Microwave Applications, John Wiley \& Sons, Inc, 2001. 